Scientific Research.

Dr. Aly A. Messallam

Professor of Organizational Studies

Faculty of Commerce

Alexandria University

Egypt

\section{Individual and Contextual}

Influences on Academic Dishon-

esty: an Investigation of Under-

graduate Student Perceptions

\title{
Introduction
}

There are two types of ethics. Type I and Type II. Type I ethics deals with how closely one's own ethical values parallel society's ethical values. If an individual fails to absorb a sense of the "rightness" or "wrongness" of certain acts from his or her family, surroundings, or society, that person is generally considered to be unethical in a type I sense. However, simply having strong beliefs about what is right and wrong does not make a person ethical which leads us to type II ethics which describe the strength of the relationship between what a person believes and how he or she behaves. Individuals who realize and believe that their actions are wrong as defined by society in general or by their profession specifically and choose to take the actions anyway have violated type II ethics (Premeaus, 1992).

When I asked my undergraduate students in my Organizational Behavior class, do they believe that cheating in exams is an ethical behavior? All of them answered "no". When I asked them, do they sometimes cheat in exams? The answer of a considerable number of them was "yes". My conversation with them regarding academic dishonesty revealed that there are many reasons for cheating in exams. The following are the most cited reasons: "we should cooperate with one another"; "when I help someone else, Iwill not loose anything"; "the educational system is already unfair"; and that "cheating is no longer considered a major problem because most people do it nowadays". It seems that what students believe is very different from what they really do. The pervious conversation between my students and me triggered the desire to investigate the issue of academic dishonesty in one of the Egyptian universities, namely Alexandria University with focus on one of its largest faculties, the Faculty of Commerce.

\footnotetext{
${ }^{1}$ An earlier version of this paper was presented at the SAM International Business Conference, Arlington, Virginia, April 8-11, 2010.
} 
According to McCabe, Feghali, and Abdallah (2008) understanding the determinants of dishonest behavior, and what affects students decisions to engage in it, and their perceptions regarding cheating may help academic institutions to prevent or at least reduce the incidence of academic dishonesty. In addition, understanding students perceptions and attitudes toward cheating, may help academic institutions to create a space in their curriculum to educate students the values and ethics they are lacking. Furthermore, it may help the administrators of academic institutions to rethink the current policies and regulations, and to focus more on developing new mechanisms to fight cheating, promote ethics, and infuse the right values in their students.

The purpose of this study is to examine students' attitudes and perceptions toward academic dishonesty across a number of individual and contextual factors. The individual factors are gender, age, year in college, major, and academic performance. The contextual factors are perceptions of peers' academic dishonesty, perceived probability of being caught, perceived severity of penalties, and perceived awareness of academic policies. To reach that end, this study tries to provide answers to the following questions:(1)What are the ethical beliefs of students?(2) How frequently do students engage in cheating behavior?(3) What is the perceived seriousness of academic dishonesty among students? (4) Is there any relationship between students'demographic characteristics and academic dishonesty? (5) Is there any relationship between the contextual variables and academic dishonesty?

\section{Literature Review}

Although cheating is universal and it occurs in all college campuses, and with much regularity (Kirkland, 2009), little work has been done on academic dishonesty outside the US especially in the Middle East (McCabe, et al., 2008). Previous research on academic dishonesty can be classified into three groups. The first group focuses on a single country such as US (McCabe, Butterfield, and Trevino, 2006; McCabe, Trevino, and Butterfield, 2002); UK (FranklynStokes and Newstead, 1995); New Zealand (De Lambert, Ellen, and Taylor, 2003); Canada (Harpp and Hogan, 1993); Singapore (Lim and See, 2001); Malaysia (Iberahim, Hussein, Samat, and Noordin, 2013; Singh and Thambusamy, 2014); Germany (Sattler, Wiegel, and Van Veen, 2015; and Taiwan (Huang, Yang, and Chen, 2016). The second group compares US students cheating behavior to that of another country students such as Poland (Lupton, Chapman, and Weiss, 2000); Hong Kong (Chapman and Lupton, 2004); UK (Salter, Guffey, and McMillan, 2001); Japan (Diekhoff, LaBeff, Shinohara, and Yasukawa, 1999); Canada (Powers, 2007); Lebanon (McCabe, et al., 2008) and Australia (Eriksson and McGee, 2015).The third group of research compares the academic dishonesty behaviors among students in different countries not including the US, such as Botswana and Swaziland (Gbadamosi, 2004). The current research adopts the pattern of the first group and applies the study in Egypt, comparing the academic dishonesty behaviors among students belonging to different individual and contextual categories. 


\section{The effect of individual factors}

Previous research revealed that a number of individual factors influenced academic dishonesty. These factors are age, gender, academic performance, years in college, type of education, and academic major.

Gender. In the review of empirical research conducted by Crown and $\mathrm{Sp}$ iller (1998), mixed results were found concerning the relationship between gender and cheating behavior. Studies conducted before 1972 revealed that the amount of cheating behaviors engaged in by females was fewer than the amount engaged in by males, while studies published after 1982 did not find significant gender differences, and on the other hand, latest studies reported that females were more likely to cheat than males. Results of the meta-analysis conducted by Whitley, Nelson, and Jones (1999) indicated that men cheated less than women in traditionally male-dominated business and economic courses. They also found that behavioral gender differences had remained relatively stable from 1960 s to 1990 s, whereas over the same time period, men's attitudes toward cheating had become more positive than women's. McCabe and Trevino (1997) found that men reported a higher level of academic dishonesty than did women. Also, Iyer and Eastman (2006) investigated the cheating behavior among business students. They found that men have a significantly higher level of academic dishonesty than women. Similarly, Smith, Davy, and Easterling (2004) examined cheating behaviors among marketing and management students, and found that males were engaged in past cheating behaviors more frequently than did fe- males. Recently, Hensley, Kirkpatrick, and Burgoon (2013) found that men had a significantly higher report rate for cheeting in comparison to women. More recently, in a survey of 79 undergraduate criminal justice students in an Australian university, Eriksson and McGee (2015) found that males view academic dishonesty as less serious and holding justifications for engaging in this type of behavior in comparison to females. However, Premeaux (2005) examined undergraduate student perceptions regarding cheating and indicated that there are no significant differences in cheating behavior based on gender.

These mixed results motivated the researcher to explore potential gender effects. The current study expects that males are more likely to engage in cheating behavior than females. This expectation is because the societal culture in Egypt tends to be more masculine than feminine. In this type of culture, females are more hesitant to engage in unethical behaviors than males. Accordingly, females are less likely to cheat.

\section{Hypothesis 1: Males will have high- er level of academic dishonesty th- an will females.}

Age. The effect of age is difficult to detect in the cheating literature (Crown and Spiller, 1998). In most studies, age is restricted to a five-year span in addition to being highly correlated with the year in college. Many studies reported significant age-cheating relationship, where McCabe and Trevino, (1997); Park, (2003); and Straw, (2002) found that younger immature students cheated more than older, mature students; juniors and seniors cheated less than fre- 
shmen and sophomores. Also, Baird (1980) and Haines et al. (1986) cited in Crown and Spiller (1998) reported that younger students cheated more frequently than older students. Similarly, Premeaux (2005) found that juniors and seniors were somewhat less likely to cheat than lower classmen. More recently, Bisping, Patron, and Roskelley, (2008) found a negative relationship between age and cheating behavior in a midsize public American university. In contrast, Barnes (1975) and Michaels and Miethe (1989) found that older students were more likely to cheat. On the other hand, Iyer and Eastman (2006) found that there was no strong evidence indicating significant differences between juniors and seniors, and freshmen and sophomores in terms of levels of academic dishonesty. In an examination of cheating and its antecedents among marketing and management majors, Smith, Davy and Easterling (2004) found that age was not a predictor of either prior cheating or likelihood of cheating behavior among those students. The current study expects to find a negative relationship between age and cheating behavior. Since the third and fourth year students are within one to two years from graduation, they are less likely to engage in unethical behavior, such as cheating, that could jeopardize their future.

Hypothesis 2a: Younger students will have higher level of academic dishonesty than will older studentts.

Hypothesis 2a: Freshmen and sophomores students are more likely to engage in academic dishonesty than juniors and seniors students are.
Academic Performance. There is a trend in previous research indicating that students with lower GPA are more likely to cheat. Crown and Spiller (1998) reported that the majority of studies indicate that students who are lower in performance may cheat more frequent1y. Also, Smith, Davy, and Easterling (2004) found that students with higher academic performance were less likely to engage in future cheating. In addition, Bisping, Patron, and Roskelley, (2008) mentioned that GPA tends to be negatively related to cheating. Similarly, Bunn et al., (1992) found that GPA and cheating were negatively correlated. Recently, Hensley, Kirkpatrick, and Burgoon (2013) found that low grades corresponded with high rates of academic dishonesty in a large public university in the USA. Another stream of research reported that there is no significant relationship between academic performance and cheating, such as Houston (1986); Kerkvliet (1994); Premeaux (2005); and Iyer and Eastman (2006). The current study expects to find a negative relationship between academic performance and cheating behavior. The lower the student's performance the greater the likelihood that he or she will engage in cheating behavior to improve his or her grades.

\section{Hypothesis3:Students with lower academic performance are more li- kely to engage in academic disho- nesty than those with higher aca- demic performance.}

Academic major. Cheating behavior has been found to be higher among business students than among their nonbusiness peers (McCabe and Trevino, 1995). Similarly, Crown and Spiller 
(1998) reviewed empirical research on business ethics and concluded that business students are more tolerant of unethical behavior than their non-business peers. Smith, Davy, and Easterling (2004) compared cheating behaviors among marketing/management majors and accounting majors, and indicated "one major difference between the two groups of students is the presence of codes of ethics. Accounting majors are exposed to professional codes of ethics from their very early classes, while the field of marketing and management do not have agreed upon codes of ethics" (p. 77). Recently, Hensley, Kirkpatrick, and Burgoon (2013) found that students in a study strategies course had a higher report rate for plagiarism in comparison to students in a science course. On the other hand, Premeaux (2005) found no significant differences between the level of cheating and major regarding Tier 1 AACSB accredited schools. However, at Tier 2 schools, Business Administration majors were more likely to cheat than other majors were. In contrast with the results of previous research, Iyer and Eastman (2006) found that non-business students engaged in higher level of academic dishonesty than business students. The current study expects that Business Administration students are more likely to cheat than other majors are, because most of the Business Administration students escaped from other majors to this less demanding one. Those students are less academically capable and are more likely to cheat.

Hypothesis 4: Business Administration majors are more likely to engage in academic dishonesty than other majors are.
Type of education. Most of the pr-evious studies differentiated between two types of education, graduate and undergraduate, and reported that undergraduate students cheated more than graduate students did (McCabe and Trevino, 1995; Crown and Spiller, 1998; Iyer and Eastman, 2006). The current study is conducted on undergraduate students only. However, this study uses two criteria to categorize students; the first criterion describes whether the student is a regular full-time or a part-time student. The second criterion describes whether the student is enrolled in the Arabic, English or French sections. The current study expects that part-time students cheat more than regular full-time students do, as they joined this type of education because they did not get the chance to be full-time students due to their low performance in high school. Accordingly, part-time students are less academically capable and more likely to regard cheating as acceptable. In addition, Arabic section students are more likely to engage in cheating behavior than English and French sections' students. This might be due to the fact that most of the English and French sections' students were educated in private schools and belong to middle class families where parents are more educated and were raised in an educational environment where cheating is less likely to take place during exams.

Hypothesis 5: Part-time students are more likely to engage in academic dishonesty than regular full-time students are.

Hypothesis 6: Arabic section students are more likely to engage in academic dishonesty than English and French sections students are. 


\section{The effect of contextual factors}

The role contextual factors play in affecting the decision to cheat has received a significant amount of recent attention (Crown and Spiller, 1998). Various attempts have been made to investigate the influence of contextual factors on academic dishonesty. McCabe and Treviño's (1993) surveyed more than 6,000 students at 31 academic institutions and found that the major contextual variables that affect students cheating are the existence or absence of an academic honor code, student understanding and acceptance of academic integrity policy, perceived certainty that cheaters will be reported, perceived severity of penalties, and the perceived peer cheating behavior.

In another study, McCabe and Treviño's (1997) investigated ', ^ . · students at nine medium to large-size American universities and found that the contextual factors such as peer cheating behavior, peer disapproval of cheating behavior, and perceived severity of penalties for cheating were more influential than the individual factors. They also concluded that peer-related factors are the most significant predictors of cheating behavior. Similarly, McCabe, et al., (2008) reported that perceptions of peers' academic dishonesty is positively related to academic dishonesty, while, perceived understanding and acceptance of academic integrity policies, perceived certainty of being reported by a peer, and perceived severity of penalties are inversely related to academic dishonesty. Similarly, Bisping, Patron, and Roskelley (2008) found that the larger the probability of being caught, the lower the likelihood that student will cheat, however, in this study the severi- ty of punishment was not a significant determinant of academic dishonesty.

Recently, Iberahim, Hussein, Samat, and Noordin (2013) found that most students participated in academic dishonesty because the lecturer did not mind the behavior, the assignment is irrelevant to the subject, and the existence of the peer-pressure environment. More recently, Reisig and Bain (2015) reported that students who perceive university authority as legitimate are less likely to express intentions to cheat on an exam.

In line with previous research, the current study expects to find a positive relationship between cheating behavior and observing others cheating. On the other hand, this study expects to find a negative relationship between cheating behavior and three other contextual factors. These factors are the perceived severity of punishment, the perceived probability of being caught during cheating, and the student's perceived awareness of academic policies.

\section{Hypothesis 7: Academic dishonesty will be positively related to the le- vel of observing others cheating. \\ Hypothesis 8: Academic dishonesty will be negatively related to perce- ived probability of being caught during cheating.}

\section{Hypothesis 9: Academicdishonesty will be negatively related to perc- eived severity of punishment.}

Hypothesis 10: Academic dishonesty will be negatively related to perceived awareness of academic policies. 


\section{Research Methodology}

\section{Variables and measurements}

The dependent variable in this study is cheating behavior. Typically, researchers use self-reported information to measure cheating. Following Premeaux (2005), students were asked how often they were engaged in cheating behavior while in college. A 4-point Likert scale was employed with the values $1=$ never cheated on an exam, $2=$ cheated once at least, $3=$ cheated more than once, and $4=$ cheated frequently.

The independent variables in this study are divided into two groups: The first group includes the demographic characteristics of the students. This group includes such variables as gender ( $1=$ Males, $0=$ Females); age (number of years); years in college $(1=$ Freshmen, $2=$ sophomores, $3=$ juniors, $4=$ seniors); previous academic performance ( $1=$ failed, $2=$ pass, $3=$ good $)$; academic major, $(0=$ General, $1=$ Business Administration, $2=$ Accounting, $3=$ Economics, 4= Political sciences, 5= Statistics, $6=$ Public Finance, and $7=$ MIS); type of education( $1=$ full-time regular students, $0=$ Part-time students); and finally, Arabic versus English and French sections $(0=$ Arabic, $1=$ English, and $2=$ French $)$.

The second group includes variables that describe the contextual factors. These variables are measured as following: First, the student perceptions of peers' behavior. Following McCabe, et al., (2008), this variable was measured by asking student how often he or she had observed other students engaging in cheating behavior. A 4-point Likert scale was employed with the values ranging from $1=$ never to $4=$ very often.
Second, the perceived probability of being caught during cheating. Following McCabe et al., (2002) this variable was measured using a 4-point Likert scale ranged from $1=$ very unlikely to $4=$ very likely. Third, the perceived severity of punishment. Student perceptions of the severity of punishment was measured using a 4-point Likert scale with values $1=$ very low, $2=$ low, $3=$ fair, $4=$ sever. Finally, the perceived awareness of academic policies. Students awareness of academic policies regarding cheating was measured using a 4-point Likert scale with values $1=$ very low to $4=$ very high.

\section{Sample and procedure}

Guided by previous studies in the field (McCabe et al., 2002; Premeaux, 2005; McCabe, et al., 2008), a questionnaire instrument has been developed to measure students' attitudes toward cheating behavior. The researcher contacted the faculty members before starting the data collection process to explain the purpose of the study and the amount of time it would take for the students to complete the questionnaire. In addition, to making sure that the faculty member will allow the researcher or one of his associates to meet with the students during his or her class. All of the faculty members agreed to cooperate and participate in the study. Most of the faculty members allowed about 15 minutes at the beginning or at the end of the lecture (according to the faculty preferences) to collect the data. It usually takes about five minutes at the beginning of the data collection process in each class to explain the purpose of the study, assure the confidentiality and anonymity of responses, and request volunteers to participate in the study. 
The students who voluntarily agreed to participate in the study were handed out a copy of the questionnaire and have been instructed to hand it in directly after they respond to all the questionnaire items. It usually takes about 10 to 12 minuets for the students to complete the questionnaire.

A stratified sample was selected to represent the population of students in the Faculty of Commerce, Alexandria University- Egypt. The population of this study includes all the registered undergraduate students by the end of the first semester of the academic year 2009-2010.

The total number of questionnaires collected from students is 1570 . Seventy-four questionnaires were excluded from the analysis because of uncompleted answers. Accordingly, the total number of completed questionnaires is 1496. Table 1 presents the classification of students in the sample according to year in college, education type, and section.

\section{Table 1}

Classification of students in the sample

\begin{tabular}{|c|c|c|c|c|c|}
\hline \multirow{2}{*}{ Year } & \multicolumn{2}{|c|}{ Education type } & \multicolumn{3}{c|}{ Section } \\
\cline { 2 - 6 } & Full-time & Part-time & Arabic & English & French \\
\hline $1^{\text {st }}$ & 387 & 153 & 385 & 125 & 30 \\
\hline $2^{\text {nd }}$ & 117 & 46 & 107 & 32 & 24 \\
\hline $3^{\text {rd }}$ & 276 & 103 & 273 & 106 & 0 \\
\hline $4^{\text {th }}$ & 326 & 88 & 300 & 114 & 0 \\
\hline Sub-total & 1106 & 390 & 1065 & 377 & 54 \\
\hline total & \multicolumn{3}{|c|}{1496} & & 1496 \\
\end{tabular}

\section{Data Analysis and Results}

There are two groups of hypotheses in this study. The first group includes the hypotheses that describe the relationship between individual factors and academic dishonesty. Students were classified into groups according to gender, age, academic major, academic performance, and other dimensions. The differences between groups regarding the cheating behavior was tested by us- ing the analysis of variance ANOVA and $\mathrm{T}$ test was used to estimate the significance of the differences between groups. The second group contains hypotheses that describe the effect of contextual factors on academic dishonesty. These hypotheses were tested by using multiple regression method. Table 2 presents the Mean, Standard Deviation, Minimum, and Maximum values for all the study variables. 
Table 2

Mean, Standard Deviation, Minimum, and Maximum for all variables

\begin{tabular}{|l|c|c|c|c|}
\hline \multicolumn{1}{|c|}{ Variable } & Min. & Max. & Mean & SD \\
\hline Cheat & 1.00 & 4.00 & 1.79 & .83 \\
\hline Gender & .00 & 1.00 & .41 & .49 \\
\hline Age & 17.00 & 26.00 & 19.74 & 1.82 \\
\hline Year In College & 1.00 & 4.00 & 2.44 & 1.23 \\
\hline Performance & 1.00 & 4.00 & 3.37 & .99 \\
\hline Majors & .00 & 7.00 & 1.53 & 2.03 \\
\hline Type & .00 & 1.00 & .73 & .43 \\
\hline Section & .00 & 2.00 & .32 & .53 \\
\hline Observe & 1.00 & 4.33 & 2.54 & .75 \\
\hline Caught & 1.00 & 4.00 & 2.49 & .63 \\
\hline Severety & 1.00 & 4.00 & 2.92 & .94 \\
\hline Awareness & 1.00 & 4.00 & 1.98 & .78 \\
\hline Reasons & 1.00 & 7.00 & 3.40 & 2.31 \\
\hline
\end{tabular}

$\mathrm{N}=1496$

Table 3 contains the correlation matrix for all the study variables. As shown in table 3, although some of the correlations are significant at the .05 level or better, the magnitude of the inter-correlations is generally low with few exceptions. The highest correlation exists between age and year in college, as expected $(r=.784, p<.01)$.
To test the effect of individual factors on cheating behavior as predicted in hypotheses 1 through 6 , the analysis of variance ANOVA was performed. Table 4 presents the results from the one-way analysis of variance (ANOVA). 


\section{Table 4}

Results from the analysis of variance (ANOVA)

\begin{tabular}{|c|c|c|c|c|c|c|}
\hline \multicolumn{2}{|c|}{$\begin{array}{c}\text { Cheating Behavior } \\
\text { (Dependent Variable) }\end{array}$} & SS & df & MS & $\mathbf{F}$ & Sig. \\
\hline \multirow{3}{*}{ Gender } & Between Groups & 14.188 & 3 & 4.729 & 20.246 & .000 \\
\hline & Within Groups & 348.516 & 1492 & .234 & & \\
\hline & Total & 362.703 & 1495 & & & \\
\hline \multirow{3}{*}{ Age } & Between Groups & 35.405 & 3 & 11.802 & 3.549 & .014 \\
\hline & Within Groups & 4961.982 & 1492 & 3.326 & & \\
\hline & Total & 4997.387 & 1495 & & & \\
\hline \multirow{3}{*}{ Year In College } & Between Groups & 24.247 & 3 & 8.082 & 5.351 & .001 \\
\hline & Within Groups & 2253.367 & 1492 & 1.510 & & \\
\hline & Total & 2277.614 & 1495 & & & \\
\hline \multirow{3}{*}{ Performance } & Between Groups & 6.818 & 3 & 2.273 & 2.302 & .075 \\
\hline & Within Groups & 1472.796 & 1492 & 987 & & \\
\hline & $\overline{T \text { Total }}$ & 1479.614 & 1495 & & & \\
\hline \multirow{3}{*}{ Majors } & Between Groups & 131.201 & 3 & 43.734 & 10.734 & .000 \\
\hline & Within Groups & 6078.702 & 1492 & 4.074 & & \\
\hline & Total & 6209.904 & 1495 & & & \\
\hline \multirow{3}{*}{ Type } & Between Groups & .258 & 3 & .086 & .445 & .721 \\
\hline & Within Groups & 288.071 & 1492 & .193 & & \\
\hline & Total & 288.329 & 1495 & & & \\
\hline \multirow{3}{*}{ Section } & Between Groups & 1.168 & 3 & .389 & 1.337 & .261 \\
\hline & Within Groups & 434.596 & 1492 & .291 & & \\
\hline & Total & 435.764 & 1495 & & & \\
\hline
\end{tabular}

As shown in table 4, there is a significant difference between males and females in terms of cheating behavior $(F=20.24, P<.000)$. The results clearly support hypothesis 1 . This indicates that males have a significant higher level of academic dishonesty than females $(M=$ 1.987 vs. $M=1.654$ ).

Concerning the effect of age differences on cheating behavior, results supported hypothesis $2 \mathrm{a}(F=3.549, \quad P<$.-
014). These results suggest that younger students will have higher levels of academic dishonesty than will older students $(M=1.974$ and 1.20 for the youngest and oldest age categories respectively). Similarly, results in table 4 supported hypothesis $2 \mathrm{~b}(F=5.351, \quad P<-$ .001) indicating that Freshmen and sophomores will have higher levels of academic dishonesty than will juniors and seniors $(M=1.89 \mathrm{vs.} 1.72)$. 
The results also supported hypothesis $3(F=2.302, P<.075)$. These results suggest that students with low academic performance will have higher levels of academic dishonesty than will students with high academic performance $(M=$ 1.933 and 1.701 for the lowest and highest academic performance categories respectively).

Testing hypothesis 4 on the variable academic major in terms of academic dishonesty, the results showed significant differences $(F=10.734, P<.000)$. These results suggest that business students will engage in higher levels of academic dishonesty than will other non-business students $(M=1.804,1.75$ 4, 1.647, 1.708, 1.347, 1.609, and 1.488 for Business Administration, Accounting, Economics, Political Sciences, Statistics, Public Finance, and MIS). Accordingly, these results supported hypothesis 4 .
Finally, as shown in table 4, results did not support hypothesis 5 and hypothesis 6 , where no significant differences in cheating behavior were found among students belonging to different types of education $(F=.445, P<.721)$. No strong empirical evidence indicated significant differences between regular full-time students and part-time students. In addition, no significant differences in cheating behavior were found among students belonging to different Arabic, English, and French sections ( $F=1.337, P<.261)$.

To test the effect of contextual factors on cheating behavior as predicted in hypotheses 7 through 10, multiple regression analysis was performed. Table 5 shows the results of regression of the level of observing others cheating, the perceived possibility of being caught during cheating, the perceived severity of punishment, and the perceived awareness of academic policies on academic dishonesty.

\section{Table 5}

Regression of level of observing others cheating, perceived possibility of being caught during cheating, perceived severity of punishment, and perceived awareness of academic policies on academic dishonesty

\begin{tabular}{|l|c|c|c|c|c|}
\hline \multicolumn{1}{|c|}{ Model } & B & Std. Error & $\begin{array}{c}\text { Standardized } \\
\text { Coefficients (Beta) }\end{array}$ & $\mathbf{t}$ & Sig. \\
\hline (Constant) & .833 & .147 & & 5.658 & .000 \\
\hline Observe & .344 & .029 & .312 & 11.926 & .000 \\
\hline Caught & -.045 & .034 & -.034 & -1.302 & .193 \\
\hline Severity & .083 & .023 & .094 & 3.643 & .000 \\
\hline Awareness & -.024 & .027 & -.023 & -.914 & .361 \\
\hline
\end{tabular}

$\mathrm{F}=40.809, \mathrm{P}<.000 \quad$ Adjusted $\mathrm{R}^{2}=.096$ 
As shown in table 5, there is a positive and significant relationship between observing others cheating and academic dishonesty $(t=11.926, P<.000)$. Accordingly, the results support hypothesis 7 . The results also show that there is a negative but insignificant relationship between the perceived possibility of being caught during cheating and academic dishonesty $(t=-1.302$, $P<.193)$. These results do not support hypothesis 8 .

In addition, the results indicate that there is a positive and significant relationship between the perceived severity of punishment and academic dishonesty $(t=3.643, P<.000)$. Accordingly, hypothesis 9 is not empirically supported. Finally, the results show that there is a negative but insignificant relationship between the perceived awareness of academic policies concerning cheating and academic dishonesty $(t=-.914$, $P<.361)$. These results do not support hypothesis 10 .

\section{Discussion}

In general, the results of the current study are consistent with the findings from previous research (McCabe, et al., 2008). Supports exist that males are significantly more likely to engage in academic dishonesty than are females. Some support also exists that younger students are more likely to cheat than older students. In addition, freshmen and sophomores students are more likely to engage in academic dishonesty than are juniors and seniors students.

Also, the results indicate that students with lower academic performance are more likely to cheat than those with higher academic performance. While this finding is different from that of Ho- uston (1986), Kerkvliet (1994), Premeaux (2005), and Iyer and Eastman (2006), it is similar to that of Davy, and Easterling (2004), and Bisping, Patron, and Roskelley, (2008). The reason is that low performers may believe that cheating will improve their grades. Specially, that students usually start in the exam by answering the questions they know their answers and then look for help from other students. Those with lower academic performance usually are not prepared well for exams; this is why they tend to cheat more than others.

In comparing cheating behaviors across academic majors, the current study found that Business Administration majors are more likely to engage in academic dishonesty than are other majors. In this study population, the first two years are for general education, students select their majors at the beginning of the third year. Consistent with the findings and rational reported by Premeaux (2005), students who achieved low performance in the basic subjects of other disciplines such as accounting, economics and MIS during their first and second years, usually select a less demanding Business Administration major. Possibly, students in this category are less academically capable and are more likely to cheat.

Classification difference had no impact on cheating. There are no significant differences between regular fulltime students and part-time students in terms of the level of academic dishonesty. Similarly, there are no significant differences between Arabic, English, and French sections' students in cheating behavior. 
In line with the findings reported by McCabe, et al., (2008), the current study found a positive and significant relationship between observing others cheating and academic dishonesty. When students observe others cheating, they convince themselves that cheating is acceptable in this faculty. Also, the results indicate that there is no significant relationship between the perceived possibility of being caught while cheating and academic dishonesty. An explanation of the absence of such relationship is that those who are unable to answer the exam questions do whatever they believe possible to copy answers from someone else with or without their knowledge or use pre-prepared cheat notes. Based on the researcher personal observations, most of the cheating behavior is performed in the last $30 \mathrm{mi}-$ nutes in a 2-hour exam. At that critical time, students ignore the possibility of being caught and focus more on copying from others with the hope that those who run the exam will not observe them. Furthermore, in these circumstances students may unconsciously ignore the severity of punishment as well. This explanation may also justify the absence of the predicted relationship between the perceived severity of punishment and academic dishonesty. Finally, the results show that there is a negative but insignificant relationship between the perceived awareness of academic policies concerning cheating and academic dishonesty. Although the relationship is in the predicted direction, it is insignificant. The percentage of students who reported that they are aware of and understand the academic polices concerning cheating is only $7 \%$. It seems that there is an absence of real awareness and understanding of academic polices and regulations.

In this study, I attempted to improve the understanding of academic dishonesty and its determinants in Arab countries, especially Egypt. There are many reasons why students get involved in cheating behaviors. Among these reasons is the large number of students per class. In addition, many faculty members use MCQ and true or false questions in order to ease the grading process for themselves. These types of questions usually invite students to cheat, especially with the absence of multiple versions of exams. Furthermore, students cheat because many are unaware of the academic policies and rules. The faculty administration should arrange an orientation session to inform new students about the academic policies concerning cheating and other dishonest behaviors. In order to prevent today's students to be tomorrow's criminals, business schools should create a space in their curriculum to teach students business ethics and values. As McCabe and Pavela (2000) recommended, students need creative and courageous leadership, grounded in the belief that students should play a vital role in designing and enforcing of academic integrity.

Finally, several limitations with this study should be noted. First, the external validity of the results of this study does not extend beyond the faculty of commerce, Alexandria University-Egypt. Second, the survey instrument used in this study was not subject to any validity and reliability tests. Third, because of the sensitivity of academic dishonesty in the Egyptian culture, some 
students may choose not to respond or not be factual in their responses.

\section{References:}

1. Baird, J. (1980). Current trends in college cheating. Psychology in the Schools, 17: 515-522.

2. Barnes, W. (1975) Test information: An application of the economics of search. Journal of Economic Education, 7: 28-33.

3. Bisping, T., Patron, H., and Roskelley, K. (2008) Modeling Academic Dishonesty: The Role of Student Perceptions and Misconduct Type. Journal of Economic Education, 39: 421.

4. Chapman, K., and Lupton, R. (2004). Academic dishonesty in a global educational market: A comparison of Hong Kong and American university business students. The International Journal of Education Management, 18: 425-435.

5. Crown, D., and Spiller, M. (1998). Learning from the literature on collegiate cheating: A review of empirical research. Journal of Business Ethics; 17, 683-700.

6. De Lambert, K., Ellen, N., \& Taylor, L. (2003). Cheating-what is it and why do it?: A study in New Zealand tertiary institutions of the perceptions and justifications for academic dishonesty. Journal of American Academy of Business, 3: 98-103.

7. Diekhoff, G., LaBeff, E., Shinohara, K., and Yasukawa, H. (1999). College cheating in Japan and the United States. Research in Higher Education, 40: 343-353.
8. Eriksson, L. and McGee, T. (2015) Academic dishonesty amongst Australian criminal justice and policing university students: individual and contextual factors. International Journal for Educational Integrity, 11: $1-15$.

9. Franklyn-Stokes, A., and Newstead, S. E. (1995). Undergraduate cheating: Who does what and why? Studies in Higher Education, 20:159172.

10.Haines, V., Diekhoff, G., LaBeff, E., and Clark, R., (1986) College cheating: Immaturity, lack of commitment, and the neutralizing attitude. Research in Higher Education, 25: 342-354.

11.Harpp, D. and Hogan, J. 1993). Crime in the classroom. Journal of $\mathrm{Ch}$ emical Education, 70: 306-311.

12.Hensley, L., Kirkpatrick, K., and Burgoon, J. (2013) Relation of gender, course, and grades to distinct forms of academic dishonesty. Teaching in Higher Education, 18: 895907.

13.Huang, C., Yang, S., and Chen, A. (2016) The relationship among students' achievement goals, willingness to report academic dishonesty, and engaging in academic dishonesty. Social Behavior and Personality: An International Journal, 44: 27-37.

14.Iberahim, H., Hussein, N., Samat, N., and Noordin, F. (2013) Academic dishonesty: Why business students participate in these practices? Social and Behavioral Sciences, 90: 152-156.

15.Iyer, R., and Eastman, J. (2006) Academic Dishonesty: Are Business 
Students Different From other College Students? Journal of Education for Business, 82: 101-110.

16.Kirkland, K. (2009). Academic honesty: Is what students believe different from what they do? A Ph.D. Dissertation, Graduate College of Bowling Green State University.

17.Lim, V., and See, S. (2001). Attitudes toward, and intentions to report, academic cheating among students in Singapore. Ethics and Behavior, 11(3), 261-274.

18.Lupton, R., Chapman, K., \& Weiss, J. (2000). A cross-national exploration of business students' attitudes, perceptions, and tendencies toward academic dishonesty. Journal of Education for Business, 75(4), 231235.

19.McCabe, D. and Trevino, L. (1997). Individual and contextual influences on academic dishonesty. Research in Higher Education, 38: 379-396.

20.McCabe, D., and Pavela, G. (2000) Some good news about academic integrity. Change, 32: 32-38.

21.McCabe, D., Butterfield, K., and Trevino, L.(2006). Academic dishonesty in graduate business programs: Prevalence, causes, and proposed action. Academy of Management Learning \& Education, 5(3), 294-305.

22.McCabe, D., Trevino, L., and Butterfield, K. (2002). Honor codes and other contextual influences on academic integrity: A replication and extension to modified honor code settings. Research in Higher Education, 43(3), 357-378.
23.McCabe, Feghali, and Abdallah (2008). Academic dishonesty in the Middle East: Individual and contextual factors. Research in Higher Education, 49:451-467.

24.Michaels, J., and Miethe, T.(1989). Applying theories of deviance to academic cheating. Social Science Quarterly, 70: 872-875.

25.Park, C. (2003). In other people's words: Plagiarism by university students-literature and lessons. Assessment \& Evaluation in Higher Education, 28: 417-488.

26.Powers, E. (2007). Cheating on a different level [Electronic Version]. Inside Higher Ed. Retrieved May 14, 2007 from http://insidehighered.com/news/2007/05/10/cheating.

27.Premeaus, S. (1992) Business ethics: a primer for managers. Journal of Property Management, Retrieved September 1, 1992 from http://www.allbusiness.com

28.Premeaux, S. (2005). Undergraduate student perceptions regarding cheating: Tier 1 versus Tire 2 AACSB accredited business schools. Journal of Business Ethics, 62: 407-418.

29.Reisig, M., and Bain, S. (2015) University legitimacy and student compliance with academic dishonesty codes. Criminal Justice and Behavior, 43: 83-101.

30.Sattler, S., Wiegel, C., and Van Veen, F. (2015) The use of 10 different methods for preventing and detecting academic dishonesty and the factors influencing their use. Studies in Higher Education, 40: 81-99. 
31.Salter, S., Guffey, D., \& McMillan, J. (2001). Truth, consequences and culture: A comparative examination of cheating and attitudes about cheating among U.S. and U.K. students. Journal of Business Ethics, 31 (1), 37-50.

32.Singh, P., and Thambusamy, R. (2014) To cheat or not to cheat, that is the question: Undergraduates' moral reasoning and academic dishonesty. $7^{\text {th }}$ International Conference on University Learning and Teaching Proceedings, 741-752.
33.Smith, K., Davy, J., and Easterling, D. (2004). An Examination of cheating and its antecedents among marketing and management majors. Journal of Business Ethics, 50: 6380.

34.Straw, D. (2002). The plagiarism of generation "why not?" Community College Week, 14: 4-7.

35.Whitley, B., Nelson, A., and Jones, C. (1999). Gender differences in cheating attitudes and classroom cheating behavior: A meta-analysis. Sex Roles, 41: 657-680. 